\title{
Vicente Riva Palacio y el periódico El Ahuizote
}

María García Flores-Chapa UNIVERSIDAD IBEROAMERICANA

Tan hábil con la pluma como con la espada, Riva Palacio representa al periodismo de oposición de la época de la Reforma, que alcanzó una virulencia y un atrevimiento sin paralelo por su eficacia para atacar al poder.

$\mathrm{E}$

n medio de los dos planes revolucionarios -de la Noria (1871) y de Tuxtepec (1876)-apareció el semanario El Ahuizote, que se presentó como un periódico de "buenos instintos", objetivo, que buscaba sólo decir la verdad, y hacer suyas las críticas y reclamaciones hechas al gobierno en el Plan de la Noria. Pero éste no era un periódico más de oposición, ya que iba más allá de la crítica política en ejercicio de una libertad de imprenta que velaba por los intereses del pueblo, advirtiendo sus errores a los gobernantes. La verdadera posición de El Ahuizote era radical y tendenciosa, oposición de partido que buscaba servir al grupo favorable a Porfirio Díaz desacreditando y ridiculizando al gobierno de Lerdo de Tejada, al que "justificadamente" se le derrocaria con el levantamiento de Tuxtepec, luego de contribuir con su objetivo de desacreditación, como lo plantearía dos años después, en el último número, que salió a la luz el 29 de diciembre de 1876: "Terminó por ahora la misión del Ahuizote; nacido para combatir los vicios de una administración crapulosa y funesta, cumplió su empeño, vio sus deseos realizados [...] Hoy se encuentran en el poder nuestros hom- 
bres, los verdaderos patriotas, los amigos del pueblo..."1

El año de 1874 se inició casi simultáneo a la aparición de El Ahuizote, el cual circuló desde el 5 de febrero de aquel año hasta el 29 de diciembre de 1876 , formando cuatro tomos. Su redacción estaba integrada por cuatro personas: Vicente Riva Palacio, Juan Nepomuceno Mirafuentes, José Ma. Villasana y Jesús T. Alamilla, y llegaría a tener una fuerte influencia durante el gobierno de Lerdo como periódico de combate, y daría lugar, posteriormente, a otros periódicos críticos como El Hijo del Ahuizote (1888, Pérez Bibbins y Daniel Cabrera); El Ahuizote Jacobino (1904, Daniel Cabrera) y El Ahuizote (1911, Miguel Ordorica), que siguieron la misma línea, quedando su nombre incluso como sinónimo de oposición y crítica al gobierno. Sin embargo, ¿cómo surge este periódico?, ¿cuáles son sus características?, ¿cuál es su contenido y formato?

Durante 1874 la situación política de México aparentaba estar en un momento de tranquilidad; sin embargo continuaba polarizada, al igual que en el contexto de la Reforma:

No se puede creer en la prensa conservadora sin tener la correspondiente confirmación de la prensa liberal y viceversa. Cada prensa, en efecto, era de combate, y tenía como misión la de presentar los hechos bajo un ángulo específico para probar, ante los lectores de su partido, lo bien fundado de su posición política a través de todas las maniobras, desde la mentira y la calumnia has-

1 "Claridades", "Despedida", El Ahuizote, viernes 29 diciembre 1876 , vol. IV, núm. 5 , p. 2. ta la ingenuidad y la verdad, sin olvicłar la sátira, la acusación, los rumores y los golpes bajos. ${ }^{2}$

Así que, para lograr cierta objetividad en la lectura de El Ahuizote, se hace necesario confrontar con periódicos de otras tendencias para establecer algunas comparaciones, por ejemplo:

- Prensa Lerdo-gobiernista:ElDiario Oficial, La Revista Universal;

- Prensa antilerdista: La Orquesta, El Siglo Diez y Nueve;

- Prensa partidaria de Porfirio Díaz: El Radical, El Correo de México.

Tambiên es necesario revisar otros periódicos ilustrados, donde de vez en cuando, los caricaturistas titulaban los dibujos con el nombre real de las personas o con el puesto que desempeñaban, para así conocer las características propias del personaje, deducir, con los datos referidos, los lugares de moda que se frecuentaban, así como las noticias y sucesos diarios, los temas tratados en el Congreso, las fiestas y días de guardar, además de hacer familiares el desarrollo tecnológico de las artes gráficas y los elementos que conforman a los periódicos, algunos de los cuales comparte El Ahuizote, haciéndolo igualmente único y diferenciándolo de los otros.

\section{ALGUNOS ANTECEDENTES DEL PERIODISMO}

El periódico lo es realmente desde el siglo XVIII, cuando tiene ya sus dos prin-

${ }^{2}$ Mc Gowan, Prensa, 1978, p. 16. 
cipales características: la noticia y la periodicidad. La noticia, contenido fundamental y original del periódico, se va enriqueciendo con toda clase de asuntos: económicos, políticos, religiosos, sociales, de propaganda, culturales; la periodicidad, parte de la aparición mensual hasta llegar a la diaria, con una o varias ediciones: matutina y vespertina.

El desarrollo del periódico fue primeramente gradual y luego en gran escala, al acrecentarse en forma notable las noticias y los medios para su adquisición y transmisión, a la par que hubo tal adelanto tipográfico que hizo posible la reproducción e ilustración de los periódicos conforme a las nuevas exigencias.

Hacia 1798 la técnica de impresión litográfica fue inventada por el alemán G.A. Senefelder, y consistía en dibujar sobre planchas de pizarra caliza con un lápiz especial compuesto de cera, jabón, cebo y negro de humo; inmediatamente después, toda la piedra se lavaba con una solución de ácido nítrico diluido y goma arábiga, y se aclaraba con esencia de trementina $y$ agua. Esta solución ataca el carbonato de cal de la piedra y no permite adherencia de grasa, pero las partes donde el compuesto del lápiz litográfico ha penetrado no son atacadas. La tinta para imprimir, parecida a la tipográfica, se adhiere a las partes dibujadas mientras es rechazada en las tratadas con solución nítrica. ${ }^{3}$

El periodismo en gran escala se puede situar desde principios del siglo

${ }^{3}$ Salvat, 1971, vol. 8, p. 2057.
XIX, ya que durante la revolución francesa cobró gran auge la prensa política con multitud de publicaciones de vida efimera y nombres pintorescos, pero cuya acción era certera; dado que el periodismo mexicano es reflejo del mundial y tiene las mismas etapas, después de la etapa formativa, "fecunda en hojas volantes y folletos noticiosos, nace el periodismo mexicano, en cuyo desarrollo cabe distinguir dos periodos: uno muy largo, que es gradual, caracterizado por haber sido informativo en sus albores y luego, por muchos años, predominantemente político, y otro de grande y completo desarrollo, conforme a las ideas periodísticas y adelantos modernos". ${ }^{4}$

En cuanto a su periodicidad se diversificaron desde el principio: mensual, quincenal, semanal, diario, y también en su contenido, pues hubo periódicos informativos, políticos, literarios, etc.; los más numerosos fueron los políticos. A cada época corresponde un periódico oficial que se encargaba de defender al régimen en vigor y otros que lo atacaban, en medio de persecuciones más o menos intensas, ya que hubo gobiernos que pretendieron amordazar a la prensa (Iturbide, Santa Anna, Díaz) y gobiernos que le dieron una libertad irrestricta (Juárez, Lerdo, Madero). En medio de tal situación, la prensa se desarrolló de manera relevante y con significación histórica de las ideas políticas en México, pues corresponde a los grandes cambios políticos del país. ${ }^{5}$

${ }^{4}$ Bravo Ugarte, Periodistas, 1966, p. 14.

5 Fernández Ledesma, Historia, 1935, p. 27. 
El periodo de la república restaurada coincide con los últimos años del desarrollo gradual del periodismo, en el cual los periódicos son todos análogos en cuanto a la pugna más seria y fundamental de la prensa: conservadores y liberales, pero diferentes respecto a la lucha política entre los candidatos a la presidencia de la república $y$ al enfrentamiento posterior que se entabla entre éstos y sus partidarios, contra sus opositores. Fue la prensa el órgano de difusión política por excelencia en el siglo xIx; tenía como misión presentar los hechos bajo un ángulo específico para demostrar a sus lectores lo bien fundada de su posición política, haciendo uso de cuaquier maniobra.

Por otra parte, la censura política y la eclesiástica de la época colonial im. pidieron la sátira contra gobernantes y autoridades, por lo que la caricatura política no pudo desarrollarse; posteriormente, con las Cortes de Cádiz, se otorgó mayor libertad de imprenta, pero es hasta el México independiente, en la época de la reforma y la república restaurada, donde se dará vuelo; sirvió indistintamente como desahogo de resentimientos, válvula de escape para atacar y defender determinados principios o para dar salida a encontradas pasiones. ${ }^{6}$

Los periódicos fueron numerosos y diversificados, tanto en tendencia política como en temática; los hubo católicos: La Sociedad Católica, La Voz de México; protestantes: La Lanza de San Baltazar; literarios: El Renaci112.

6 Véase Pruneda, Caricatura, 1958, pp. 110 miento, La Tribuna; infantiles: Los Chiquitines, El Amigo de los Niños; científicos: La Ilustración Espírita, Revista Científica Mexicana; comerciales: El Boletín Comercial de México; político-gobiernistas: El Federalista, El Eco de Ambos Mundos; políticos de oposición: El Padre Cobos, La Orquesta, El Monitor Republicano, El Siglo Diez y Nueve, El Ahuizote, etcétera.

Parte de la idiosincrasia del pueblo mexicano es el deseo de ver la vida sin los tintes graves o trágicos que le acompañan; sobre esto, Luis Reed Torres señala, en "Antecedentes del periodismo humorístico", lo siguiente:

Un innato ingenio y picardía que le permite enfrentar hasta las tareas más dificiles, celebrar mejor un triunfo, pero también arrostrar las más graves desgracias incluyendo la muerte. Esta cualidad envidiable que muy pocos pueblos del mundo pueden preciarse de poseer, le asegura, así mismo, una protesta dinámica y muchas veces positiva, [...] o un encendido elogio las más de las veces no razonado probablemente, pero sí manifestado sinceramente. Es en ocasiones tan incisiva y común esta práctica del mexicano, que no pocas veces se han equivocado en sus juicios y criticado humorísticamente a algún dirigente político que no ha hecho más cosa que servir a su pueblo, y teniendo en cuenta esta singularidad de nuestra gente, no es de extrañarse la aparición de dichas publicaciones humoristicas en la historia de nuestro periodismo. ${ }^{7}$

El periódico ilustrado en México, como en el mundo, logró gran auge en

7 Torres, "Antecedentes", 1980, p. 21. 
el siglo XIX gracias a la litografia; ésta fue una forma relativamente nueva de las artes gráficas pero que alcanzó una rapidísima y brillante difusión. Vino a México con el italiano Claudio Linati en 1826 cuando fundó el periódico El Iris (1826), donde aparecieron sus litografias pero, debido al fuerte control de la prensa existente, el italiano salió del país el mismo año en que llegó; la nueva técnica se usó para ilus. trar catálogos, planos militares y topográficos, ya que el aprendiz que tuvo Linati, durante su corta estancia, fue un joven oficial, Ignacio Serrano, quien aprendió rápidamente el arte tipográfico.

Desde el punto de vista plástico, los trabajos esporádicos de caricaturas que aparecen en periódicos como El Iris y El Correo de la Federación reflejan el influjo de las caricaturas inglesas con leyenda, empleadas durante las guerras napoleónicas y con las cuales en Europa se inauguró esta forma de expresión artística como arma política para impresionar a los lectores. Pero en esas décadas el arte tipográfico en México apenas iba a la zaga del modelo tradicional que le marcaban las ediciones españolas y francesas, y avanzaba con precarios tanteos.

En 1836 Ignacio Cumplido imprimió las primeras entregas de ElMosaico Mexicano, que contenía estampas litográficas de Rocha y Fourier; desde entonces, las grandes impresoras emplearon la litografia para ilustrar libros y algunos periódicos como $\mathrm{El}$ Recreo de las Familias (1838, Imp. Galván), El Semanario de las Señoritas Mexicanas (1841, Imp. García Torres), El Museo Mexicano (1843, Imp. Cum- plido), El Católico (1846), La Ilustra. ción Mexicana (1850, Imp. Cumplido), El Renacimiento (1869, $1^{2}$ época, Imp. Díaz de León), México y sus Costumbres (1872, Imp. Gallo y Cumplido), etcétera.

El gran Ignacio Cumplido lanza en 45 un volumen: El Gallo Pitagórico, del célebre polemista Juan Bautista Morales. Frontispicio litográfico cuajado de graciosos atributos. Espléndido retrato del autor y litografia fuera de texto desbordante de sátira, ilustran el volumen. ${ }^{8}$

Apenas apareció $E l$ Gallo Pitagórico, el maestro de la calle de Palma, el señor Lara, contestó con las obras de Fígaro; se inauguró así un nuevo género de oposición a través de caricaturas con explicaciones irónicas y jocosas. En 1849 apareció El Tío Novilla, de gran mordacidad en sus ataques y maestría en sus dibujos, donde el anónimo dibujante se burlaba de la lujuria y rapacidad de los frailes y se mofaba del gabinete de Santa Anna, ridiculizando a sus ministros y denunciando los manejos de traición de los alamanistas.

En 1861 comenzó a publicarse en México La Orquesta, que duró hasta 1874. Nunca se habia lanzado a combate un campeón tan vigoroso. La sátira cáustica del texto halló en las litografias un arma terrible. Dos colosos del humorismo se habían encontrado: Riva Palacio y Constantino Escalante; ellos hicieron más con su pluma y su lápiz que muchos generales con sus ejércitos. ${ }^{9}$

${ }^{8}$ Fernández Ledesma, Historia, 1935, p. 76.

9 Ibtd., p. xxv. 


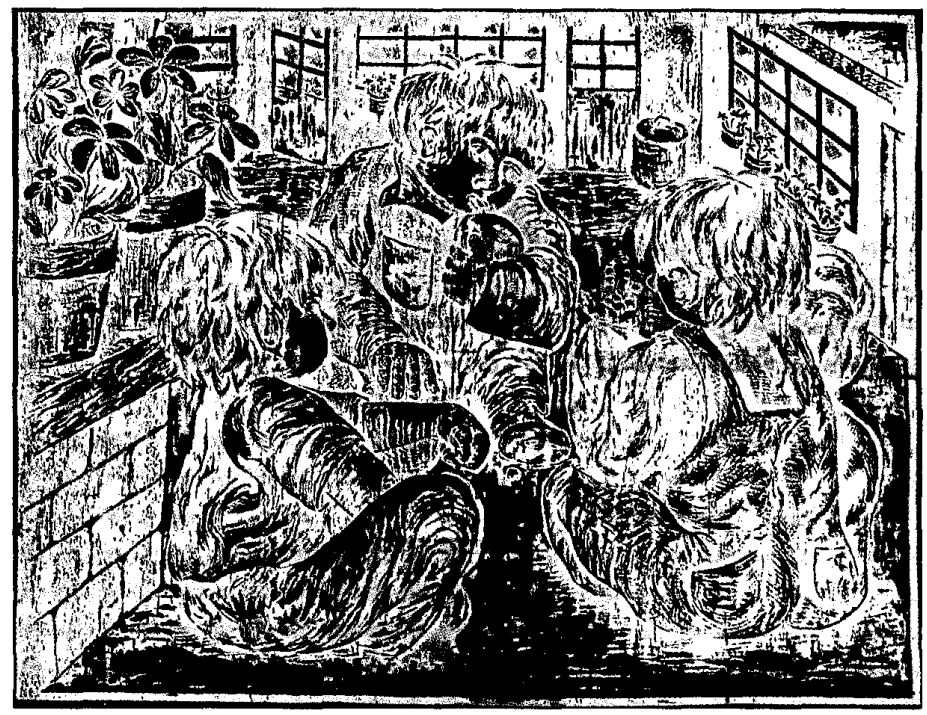

Es así como se publican periódicos en los que la caricatura es parte importante, como El Monarca, El Padre Cobos, La Historia Danzante, ElAhuizote, etc., que se unen a periódicos de fuerte oposición al gobierno, como $E l$ Monitor Republicano, publicado desde 1844 por Vicente García Torres, y El Siglo Diez y Nueve, editado por Ignacio Cumplido desde 1841.

La litografia resultó especialmente apropiada - con sus grandes posibilidades de grises, negros y luces- para dejar huella clara del ingenio fácil, de la gracia satírica y la picardia, sobre todo porque sin las limitaciones de laboriosidad y de esfuerzo que exigen otras técnicas de grabado, permitía a la mano del artista toda la agilidad y versatilidad necesarias para que sus ideas y ocurrencias pasaran inmediatamente de la imaginación creadora a la punta de su lápiz, evitando que perdieran frescura e ingenio y haciendo de la prensa el vehículo de educación politica del pueblo analfabeto que recibía, en las imágenes de la caricatura, la síntesis de una circunstancia particular, de una situación embarazosa y ridícula que atentaba contra los intereses, emociones o simpatías de la gente del pueblo, diestra en captar la expresión del símbolo, del programa o del jeroglífico, y que por ello gustaba y comprendía la caricatura.

Aquí, como en otras partes, los mejores litógrafos, grabadores y dibujantes pagaron tributo a la caricatura, haciendo de su habilidad para captar el carácter de los sujetos un arte. Los he- 
chos glosados por la pluma o el lápiz de esos artistas nos informan siempre su posición de ataque o de defensa frente a las libertades y derechos del hombre, en sus aspectos económico, político o social, que se fueron esclareciendo a través de la evolución constitucional de México. La lucha se inicia en el campo de batalla y pasa de ahí al de las ideas en la tribuna parlamentaria y después a la arena abierta, más ardua todavia, del palenque periodístico. La caricatura cobra especial significación porque tiene ante sí no sólo el desempeño de una función artística, sino la responsabilidad de una tarea social dentro de las lides del periodismo, y ha de enfrentarse a sus opositores comunes; surge así el periódico ilustrado como testimonio de una época con gran valor histórico y artístico.

Entre los pensadores de uno y otro bandos de la época, se alinearon los principales contingentes de comentadores gráficos, con una variedad de manifestaciones comparable a la de los géneros literarios. De un lado los seguidores de las ideas liberales, que gozaban de las simpatías populares y hallaban eco en la mayoría del público, y, por otro, la reacción, el alto clero y la aristocracia latifundista, unidos al militarismo. Maravilloso campo de lucha ideológico y político para el desenvolvimiento de la caricatura, que será considerada como arma favorita en el ataque, lo mismo que en la apología o la defensa de los principios que se sustentaban. "El fin era la doctrina y el medio era el periódico [...] y escritos para expresar una doctrina, la condición sine qua non de su éxito, era la libertad de expresarla, por eso la exi- gían y por eso usaban y abusaban de ella." 10

La caricatura como medio de comunicación nace ante la necesidad de denunciar una inconformidad frente a la sociedad, haciendo alusión a la realidad de la que emerge y a la que se debe, sin lo cual no habría comunicación [...] la caricatura transmite el mensaje al espectador a través de un código, cuyo conocimiento permite descifrar el mensaje. La comprensión de la caricatura presupone una comunidad a la cual se pertenece en el momento en el que el mensaje es emitido; [...] la caricatura tiene una característica dual, puede ser mera alusión transitoria o caracterización perdurable, $o$ ambas cosas; para realizarla, el artista cuenta con instrumentos formales, tales como la línea, el color, el espacio y la perspectiva, así como elementos simbólicos: la metáfora, la analogía, el mito, ello para hacer que el mensaje sea entendido con mayor facilidad para mayor número de personas de cualquier latitud y época. ${ }^{11}$

\section{LA REDACCIÓN DE EL AHUIZOTE}

En 1874 la redacción del semanario estaba formada por cuatro personas: Vicente Riva Palacio, Juan Nepomuceno Mirafuentes, José Ma. Villasana y Jesús T. Alamilla, y generalmente el cuerpo de redactores de revistas y periódicos se componía de tres o cuatro personas que compartían la misma ideología, puestas virtualmente bajo 38.

${ }^{10}$ Cosío Villegas, Historia, 1955, vol. 2, p.

${ }^{11}$ Acevedo, “Obra", 1975, pp. 10 y 12. 
la dirección de un redactor en jefe, pero en ocasiones un solo escritor era totalmente responsable de la preparación y edición del periódico o asumía ese trabajo en caso de ausencia de alguno de sus integrantes, como ocurrió con El Ahuizote en 1875, cuando el licenciado Luis G. de la Sierra siguió encargándose de la redacción al incorporarse a la lucha armada Vicente Riva Palacio y Juan N. Mirafuentes; raras veces se admitían colaboradores ajenos a la redacción, y en caso de haberlos pertenecian a la misma comunidad política de los integrantes de aquélla.

En los primeros números del semanario se hicieron referencias a sus colaboradores, pero de manera burlona, característico de Riva Palacio, como puede apreciarse en el texto del viernes 20 de marzo de 1874:

Colaboración. Como algunas personas desean conocer la lista de colaboradores del Ahuizote, no tenemos escrúpulos en publicarla, y es ésta: Parte política, derecho constitucional, municipal, internacional, federal y provincial: señores Porrás; Fulcheri; Omarini; Recamier; don Ignacio (fonda Guillow); Carnitas el del Conejo Blanco; Balcárcel, y el señor de la nevería de Santa Clara. Táctica, fortificación, estrategia, balística y vaulauventi: señorgeneral Mejia; señor capitán idem; señor general Núñez; señor teniente coronel Plassant (pastelería de Plateros); señor comandante P. Coste (pastelería de la Profesa); don Lino (pastelero ambulante de cajoncito). Marina náutica, cabotage (sic): el excelentísimo señor ministro de Marina; el señor Ladrón de Guevara, propietario de la fonda El Grumete; los señores cocineros de la fonda La Marina; las señoras trajineras de la laguna de
Chalco; la comisión de Aguas del Ayuntamiento; el señor don Cayetano Gómez Pérez, dueño de los baños de la Santísima y fiscal de orden suprema de la Suprema Corte, y su viejo administrador don Francisco Barrón. Literatura, variedades, modas, teatros, comidas, etc.: señor presidente don Sebastián Lerdo de Tejada; señor don José Ma. Iglesias; señor don José Ma. Lafragua; la sombra de Chole Aycardo; uno de los señores que representaban en el jacalón de la Exposición; don Blas el de las tarifas; Pompeyo, el cerdo sabio, el burro sabio (si aún es vivo); los niños de Australia, $y$ algunos humildes y oscuros partidarios de la actual administración. ${ }^{12}$

En el último número del semanario, del viernes 29 de diciembre de 1876 , se hace un resumen de la actuación de los redactores y se presentan sus retratos en la página 8 , una vez que los hombres de su partido han triunfado $y$ los redactores recogen el premio a su trabajo:

Los señores don Vicente Riva Palacio y don Juan Nepomuceno Mirafuentes fueron los fundadores del Ahuizote, y la época de oro de este periódico se debió a las bien cortadas plumas de estos notables escritores; chispeante y correcto el primero, saturaba de sal ática todos sus escritos, siendo su sátira fina siempre y graciosa. Enérgico y terrible el segundo, lanzaba duros anatemas al gobierno inmoral de Lerdo, y sus vigorosos editoriales hacían temblar al tirano. Más tarde ambos escritores abandonaron las lides periodísticas y desenvainaron honrosamente sus espadas en de-

12 "Colaboración", El Ahuizote, viernes 20 marzo 1874 , vol. 1 , núm. 7, p. 7 . 
fensa de la libertad. Al ausentarse los señores Riva Palacio y Mirafuentes, siguió encargándose de la redacción del Ahuizote el licenciado Luis G. de la Sierra. Nada podemos decir en nuestro propio elogio: combatimos al tirano y cumplimos con un deber. Completaron el cuadro de nuestra redacción el famoso caricaturista Villasana, a quien auxilió el aprovechado joven Alamilla. ${ }^{13}$

José Ma. Villasana, periodista, dibujante y uno de los caricaturistas más celebrados y hábiles, nació en Veracruz en el año de 1848 , colaboró en periódicos como La Orquesta, La Historia Danzante, El Mundo Ilustrado, Méxi. co Gráfico y El Ahuizote, y se le debió en gran parte la popularidad alcanzada por este semanario. Jesús T. Alamilla, caricaturista en 1857, colaboró con Villasana en varios periódicos, y en $E l$ Ahuizote aportó su habilidad como caricaturista político.

El general Juan N. Mirafuentes fue médico y político, y ejerció el periodismo político en La Pluma del Pueblo, El Ferrocarril y El Ahuizote; escribió en contra de la intervención francesa y después en contra del gobierno de Lerdo de Tejada. Según Cosío Villegas:

Juan N. Mirafuentes, general y doctor, escribía de todo y con una pertinacia extraordinaria; juzgaba muy tosca y ordinariamente problemas y personas, pero fue un rebelde constante $[. .$.$] fue$ siempre escritor truculento [...] No tenía sentido de la ponderación y menos

13 "Nuestra redacción", El Ahuizote, viernes 29 diciembre 1876 , vol. $\mathrm{v}$, núm. 5, p. 7. del humor [...] no tomó las armas en la revuelta de La Noria, permaneció en México, proclamando en la prensa la pureza de la insurrección y el vicio del gobierno [...] Por otro lado, Mirafuentes era un hombre bueno, honrado, sincero, pero vivía en la esterilidad de la oposición y en la soledad del rebelde vencido [...] Nada tiene de extraño su visión sombría del país, visión que no modificó mucho a la hora del triunfo tuxtepecano. $^{14}$

Vicente Riva Palacio, político, escritor y militar nacido en la ciudad de México en 1832, inició su carrera política en 1855, fue diputado suplente en el Congreso que elaboró la Constitución de 1857 y diputado propietario al triunfó liberal para 1861-62. Atacó duramente a los conservadores y participó activamente en la lucha contra los franceses; de regreso a la capital en 1868, tomó posesión del cargo como magistrado de la Suprema Corte de Justicia hasta 1870 , cuando renunció por considerar que entre su criterio y el del Tribunal Supremo "existía una contraposición absoluta de los principios constitucionales que profesaban". ${ }^{15}$ En política era liberal y republicano, creía firmemente en la necesidad de aplicar la Constitución del 57 y las Leyes de Reforma y, como todos los constituyentes, pugnaba por un balance más justo entre los tres poderes, dado que tanto Juárez como Lerdo gobernaron gran parte del tiempo con facultades extraordinarias alu-

${ }^{14}$ Cosío Villegas, op. cit., La vida soctal, pp. 415 y 489 .

15 Ortiz Monasterio, "Prólogo", 1979, p. IX. 
diendo a la excesiva intervención del poder legislativo; tal medida, necesaria para dirigir al país, para muchos iba más allá de lo necesario y contravenía el espíritu de la Constitución de 57. Además, los dos pretendieron reelegirse, siendo esto, entre otras razones, lo que hizo que los gobiernos de ambos enfrentaran una fuerte oposición. Riva Palacio presentó esa oposición franca, aunque por su parte tuvo motivos para distanciarse de estos gobiernos. Con Juárez sus diferencias se remontaban a la guerra de Intervención. ${ }^{16}$ Con Lerdo, aunque Riva Palacio compartía la ideología liberal, sus relaciones fueron más bien frías y se distanciaron definitivamente en 1873 , cuando el general Riva Palacio perdió la presidencia de la Suprema Corte de Justicia ante José Ma. Iglesias, amigo y colaborador de Lerdo, pese a que era el candidato más popular.

Así, Riva Palacio se convirtió en un opositor de los gobiernos de Juárez y de Lerdo de Tejada, pero su oposicion no fue pasiva; los combatió como diputado en el Congreso, y sobre todo a través de los periódicos. El periodismo fue una actividad que Riva Palacio cultivó durante toda su carrera; desde 1861 fue redactor de La Orquesta, y cuando Júarez trasladó el gobierno a San Luis Potosí fundó $\mathrm{El}$ Monarca junto con Guillermo Prieto y Juan de Dios Arias, ilustrado por Villasana. En Huetamo, Michoacán, fundó El Pito Real, periódico que fue el primero en publicar la popular canción "Adiós mamá Carlota". Después de la guerra

16 Ibid., p. XII. colaboró en casi todos los periódicos de tendencia liberal, como El Correo del Comercio, El Constitucional y otros más. Los artículos de Riva Palacio se caracterizaron por su crítica aguda, en la que abunda una sátira punzante y humorística.

En 1867, con el triunfo de Juárez y el partido de la Reforma, La Orquesta aparece bajo la dirección del general Riva Palacio, quien usaba el pseudónimo de Juan de Jarras. Riva Palacio "se dio cuenta del valor de la caricatura como arma política; lecciones que habría de poner en práctica al fundar el famoso Ahuizote, periódico que tan importante papel habría de desempeñar en la política mexicana durante la presidencia de Lerdo de Tejada". ${ }^{17}$

El 1 de noviembre de 1873 Riva Palacio publicó un diario comparable a los mejores de la época; lo llamó $E l$ Radical, para indicar la severidad con que enjuiciaría a hombres, hechos y circunstancias, y así los juzgó èn verdad. A finales de ese año Riva Palacio se separó de La Orquesta por diferencias ideológicas con los colaboradores; mientras él apoyaba a Porfirio Díaz, Manuel C. Villegas lo atacaba; en febrero de 1874 apareció un nuevo periódico de oposición, cuyo fin no era sólo la crítica política ilustrada con alguna caricatura alusiva, sino el desprestigio y la ridiculización de Lerdo, de sus ministros, del Congreso, de la Corte, socavando su nombre y su prestigio por medio de una sátira punzante y con la mitad del periódico en caricaturas como elemento de oposición.

${ }^{17}$ Leal, "Contenido", 1958, pp. 328 y 336. 
El Ahuizote es, hasta cierto punto, la continuación de La Orquesta; aunque por lo general aquél es considerado como el primero que usó la caricatura con fines políticos, no hizo sino seguir la pauta establecida por Carlos R. Casarín y Constantino Escalante, lección que Riva Palacio no echó en saco roto.

En 1875 Riva Palacio se entregó a la tarea de escribir una Historia de la administración de don SebastiánLerdo de Tejada, en la que intentó estudiar las "razones históricas por las cuales ese gobierno pasó de la popularidad más espontánea y vehemente, hasta el desprestigio más completo". ${ }^{18}$ Dicho trabajo lo concluyó otra persona, ya que Riva Palacio, el general Rocha y otros sospechosos de hacer preparativos revolucionarios, fueron confinados a poblaciones determinadas. Al primero se le señaló San Juan del Río, pero renunció a su empleo de general para evitar el cambio. El Monitor, interpelando al Diario Oficial sobre el particular, decía que la complicidad de Riva Palacio en la conspiración era falsa, y que se tomaba como un pretexto para desterrar al redactor de un periódico satírico que hacía violenta oposición al gobierno de Lerdo, empleando el arma del ridículo contra él, poderosísima en nuestro país. ${ }^{19}$ Dando la impresión de que continuaría acosando al gobierno con una serie aparentemente interminable de articulos en El Ahuizote, Riva Palacio

\footnotetext{
${ }^{18}$ Riva Palacio, Historia, p. 2.

19 Cosmes, Historia, 1901, vol. XXII, pp. 692-
} 693. abandonó de pronto la ciudad de México para llegar al Mineral del Oro el 20 de mayo. "De una pluma tan brillante, por lo menos, como su espada, principia por adoptar el nombre de Plinio Pretis en la clave revolucionaria [...] Después calladamente se traslada a Oaxaca a sumarse a las fuerzas de Porfirio, con las que aparece en Tecoac." 20

En octubre de 1876 se promulgó una ley que suprimía la libertad de prensa, y El Ahuizote publicaba una última palabra haciendo un resumen de actividades y clarificando su postura política:

Nuestro periódico, fundado hace tres años, y sostenido por el favor público, ha cumplido su misión. Hizo una fructuosa propaganda de desprestigio para el actual gobierno, logrando hundirlo en el abismo del ridículo. El género satírico ha sido cultivado por nosotros, si no con inteligencia, con oport unidad al menos, puesto que en toda la república hemos dado a conocer a los hombres de la situación en su espantosa deformidad, rodeándolos de la burla y del desprestigio $[\ldots]$ nuestros redactores han sufrido uno a uno los rudos ataques del gobierno, que contra ellos ha desencadenado la tempestad de sus iras, y sin embargo, el periódico ha continuado imperturbable la tarea que se impuso, de condenar los actos inmorales de un poder corrompido y corruptor [...] Hemos defendido también con brío los principios salvadores proclamados por el plan de Tuxtepec, sosteniendo que la democracia sólo puede afianzarse rodeando de inmensa libertad al sufragio

${ }^{20}$ Cossio Villegas, Historia, La vida social, pp. $850-851$. 
universal y conquistando para el completo triunfo de las instituciones que nos rigen la importante reforma de la no reelección. Cumplida ya la tarea que nos impusimos, y siéndonos imposible continuar defendiendo los sanos principios, abandonamos el periodismo, persuadidos de que la cuestión política ha terminado y de que lo que resta hacer corresponde a las armas. Dentro de muy pocos días el tirano y sus humildes siervos recibirán el castigo a que se han hecho acreedores por sus abominaciones, por la tiranía del primero, por el servilismo, la abyección y la indignidad de los otros. Entonces, cuando se dibuje en el horizonte la aurora de la libertad, podremos volver tranquilos y respetados al estadio de la prensa, del que hoy nos aparta bruscamente la iniquidad. ${ }^{21}$

Triunfante el Plan de Tuxtepec, Porfirio Díaz llega al poder en noviembre de 1876; Riva Palacio fue incluido en su gabinete como ministro de Fomento, Colonización, Industria y Comercio, y Juan Mirafuentes como gobernador del Estado de México.

El 1 de diciembre de 1876 reaparece El Ahuizote, afirmando que

en un abrir y cerrar de ojos El Ahuizote ha mordeceado de lo lindo a tío Chepe José Ma. Iglesias, pero ofrece que no será la última vez porque tiene la mala costumbre de meterse en todo, y de querer enderezar lo que va torcido, y como zurró la pavana a don Sebastián, así zurrará a tío Chepe, y hasta al mismísimo Porfirio el día que no se ande

21 "Editorial. Nuestraúltima palabra", El Ahui$z o t e$, viernes 13 octubre 1876, vol. III, núm. 41, p. 2 . derecho, porque no tiene compadrazgos, ni compromisos, nì hace caravanas, sino que es claridoso, ése es su modito y se respetará acá. ${ }^{22}$

Pero el 29 del mismo diciembre se despide de sus lectores, ya que considera terminada su misión:

Terminó por ahora la misión del Ahuizote; nacido para combatir los vicios de una administración crapulosa y funesta, cumplió su empeño, vio sus deseos realizados [...] Hoy se encuentran en el poder nuestros hombres, los verdaderos patriotas, los amigos del pueblo; podrán cometer errores, pero una administración naciente debe ser respetada porque no tiene aún en su mano los elementos de un gobierno constituido para proseguir su marcha. No seremos nosotros los que opongamos obstáculos y entorpecimientos a un poder que, saliendo de entre los escombros que dejó la revolución, comienza apenas a reconstruir el orden administrativo [...] Tampoco estamos dispuestos a degradar nuestro carácter de escritores libres, entonando hosannas a los que gobiernan porque, aunque somos sus sinceros y leales amigos, no queremos se nos confunda con aquel enjambre de periodistas asalariados. [El Ahuizote] nació para combatir a los tiranos, para combatir los fueros de la Constitución. Hoy, que gracias a la revolución regeneradora de Tuxtepec cayó la tiranía y se mira ya la aurora de la libertad, ha terminado su misión y se entrega al mutismo, pero no muere, porque algún día se levantará erguido y terrible si los gobernantes, cerrando los oídos a la

22 "Claridades", "Slutem pluribus", El Ahuizote, viernes 1 diciembre 1876 , vol. IV, núm. 1 , p. 2. 
voz del patriotismo, intentasen esclavizar al pueblo. Entonces nuestro periódico volverá $[\ldots]$ combatirá a cualquiera que conculque la Constitución de 57, que ofenda la democracia, que viole los derechos del hombre y que tiranice al pueblo [...] Si el ilustre general Porfirio Díaz y sus dignos colaboradores en el gobierno respetaren al pueblo, bien podrá colocarse una losa sobre la tum. ba del Ahuizote, más si por desgracia no fuere así, saldrá de su sepuicro como Lázaro cuando la patria le diga: LEVÁNTATE Y ANDA. 23

\section{CARACTERÍSTICAS DE ESTRUCTURA}

El análisis de la estructura de un periódico no es muy diferente al objeto del análisis del contenido.

El uno y el otro tienen por objeto revelar lo que un periódico ha querido comunicar a sus lectores de las informaciones de los artículos y presumir la influencia que una lectura normal del periódico ha ejercido en el lector [...] De lo que más se impregna el lector $-\mathrm{y}$ esto lo sabe muy bien la redacción del periódico- es menos del texto en sí. con todas sus características de estilo y disposición de los hechos y de las ideas, que de la forma en que este texto ha sido captado por los ojos del lector y luego registrado en su memoria, ${ }^{24}$

por lo que no debe descuidarse el estudio de las cuestiones externas que confieren a la información o al artículo un valor peculiar: "en efecto, un

23 "Claridades", "Despedida", El Ahutzote, viernes 29 diciembre 1876, vol. $\mathrm{N}$, núm. 5, p. 2.

${ }^{24}$ Kayser, Períbico, 1966. periódico forma un todo, una unidad en la que ningún elemento es disociable sin que se altere su autenticidad". 25

La aparición de $E l$ Ahuizote no fue mera casualidad, sino el resultado de un bien pensado plan de ataque, como puede percibirse desde el nombre dado a la publicación; pero ¿qué es un ahuizote? Un ahuizote era un animal de poca importancia, hasta el momento en que representó a un semanario político de oposición.

Ahuizote (del náhuatl, ahuizotl): animal semifabuloso que se cree era de la familia de las nutrias. Llamábase comúnmente "perro de agua". Era un habitante del lago central del valle y pereció durante la etapa del predominio azteca $(1270$ a 1521). Era, al tenor de las descripciones, del tamaño de un perro chico con pelo sumamente liso y con orejas y trompa alargadas y lisas. Se le atribuía una mano en la cola y las otras cuatro semejantes a la de los monos antropoides. Se decía habitar en el lago y estar consagrado a Tláloc. Atisbaba al que venía a sacar agua y se apoderaba de él con su mano de cola, y si tardaba en venir, lloraba como un niño para atraer la compasión y hacer que llegara a la ribera. La palabra pasa al lenguaje común como símbolo de ser molesto y hostil. ${ }^{26}$

Puede decirse que se tomó para el periódico el nombre de ahuizotl por su connotación de molesto y hostil, y se castellanizó a ahuizote, y el animal se transformó de la familia de las nutrias en uno de la "familia de los de-

25 Ibid.

${ }^{26}$ Porrúa, vol. 1, p. 4. 
monios", como puede apreciarse en la ilustración del título; se trata de un hombrecillo regordete con orejas puntiagudas, alas de murciélago y mirada maliciosa, con un tridente empuñado, de acuerdo con la tradición religiosa que representa así a los demonios para hostilizar a los que actúan mal. Lo que se pretendía es que no fuera algo terrible que infundiera miedo, sino feroz pero de buenos instintos: la presentación entraña una expresión de bondad para lograr aceptación en los lectores y justificar los ataques contra el mal, representado por el gobierno de Lerdo. Recuerda otros periódicos que ya gozaban de la aceptación del público: La Orquesta, del cual se convierte en competencia, y La Historia Danzante, con los cuales se notan algunas similitudes, una de ellas la aparición, en su presentación, de demonios con tridente.

El Ahuizote, "Semanario feroz aunque de buenos instintos; pan, pan; y vino, vino; palo de ciego y garrotazo de credo y cuero, y tente tieso", tiene como leyenda de identificación un proverbio que se asocia con aquello que es verdad, y recuerda a otros periódicos con leyendas sarcásticas como El Padre Cobos. 'Periódico campechano, amante de decir indirectas y con caricaturas"; Los Padres del Agua Fría. "Periódico hidropático, medicinal y utilísimo para los reumáticos políticos, nada de dolo y engaño. Rasero a todos iguales" [México, diario liberal satírico con caricaturas, 1856], El Pobre Diablo. "Periódico raquítico, estrambótico y ridículo, con ribetes de político, erótico, y aun físico, político y retórico pero redactado por jóvenes maléficos. Si os dan un bofetón, descargad cuatro sin mirar en qué mejilla" [Tlaltenango, Zacatecas, semanario, 1856].

El Ahuizote, que se publicaba cada viernes (a excepción del primer número), apareció del jueves 5 de febrero de 1874 hasta el 3 de octubre de 1876; reapareció el 1 de diciembre y terminó definitivamente el 29 del mismo mes. Existe una errata en el núm. 38: la fecha dice viernes 24 de octu. bre, cuando debería ser viernes 23 de octubre de 1874.

No se encontró ningún anuncio previo o presentación, tampoco editorial o texto que especifique tendencia, estilo, objetivos o filiación política. Como editores se presentan J. Ma. Villasana y Cía., y el responsable Homobono Pérez; la redacción estaba localizada en la calle de San José el Real núm. 21, siendo éste el domicilio legal del periódico. La impresión de los primeros once números se hizo en la Imprenta de los Niños, en la esquina de la calle del Espíritu Santo y Portal de la Fruta; a partir del número 12, del 24 de abril de 1874 , se hizo en la Imprenta de León y White, propiedad de Francisco Díaz de León y.Samuel White, en la calle de Lerdo núm. 2; en los dos años siguientes cambiaron varias veces de imprenta. Cada número indica que "Los corresponsales se entenderán con el Sr. don Filomeno Mata, en la $2^{a}$ de Vanegas núm. $61 / 2^{\prime \prime}$. Se hace diferencia entre corresponsales y colaboradores, pero con respecto a dichos corresponsales no se dice ni si son exclusivos del semanario, ni siquiera quiénes eran y dónde se encontraban; no hay participaciones firmadas, 


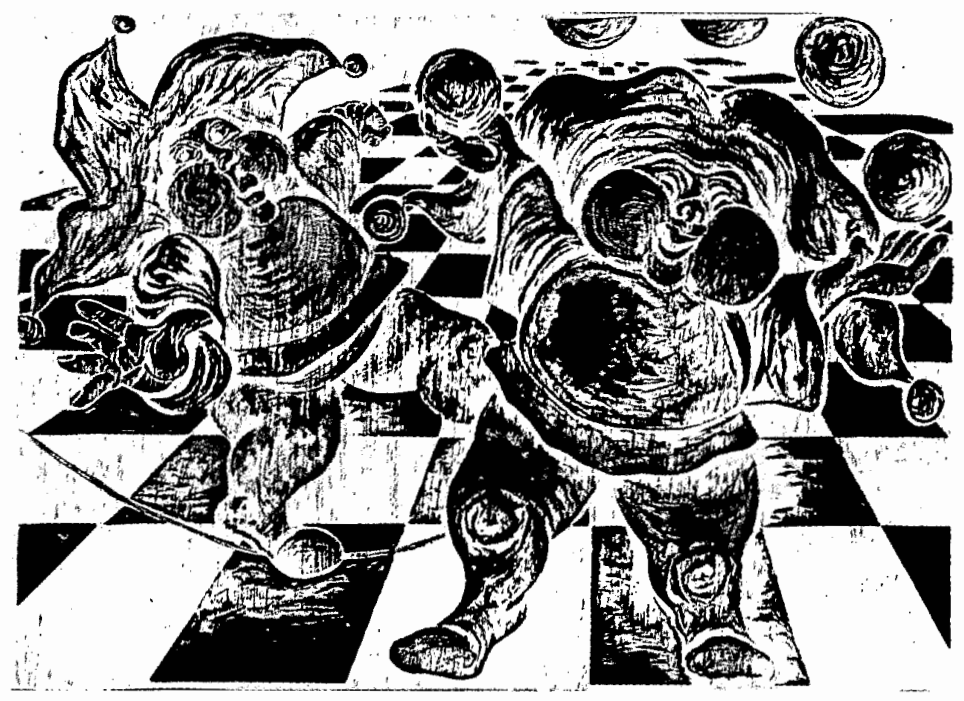

a excepción hecha de "El Fandango (cuadro macuteno)", firmada por Heberto (pseudónimo de Luis G. Ortiz), y mencionan sólo cambios o defunciones de colaboradores foráneos.

Tampoco se encontró noticia alguna sobre el tiraje semanal del periódico; la única al respecto es la que hace referencia en su segundo número, en que se comenta que el primer número se agotó y se reeditará para cubrir las solicitudes. ${ }^{27}$

En las "Condiciones" se aclaraba que tenían suscripciones a domicilio y se vendía al público en algunos expendios comerciales: "Librería Aguilar y Ortiz, $1^{\underline{a}}$ de Sto. Domingo núm. 5;

27 "Muy interesante", El Ahuizote, viernes 13 febrero 1874 , vol. I, núm. 2, p. 7.
Agencia de Delano Hermanos, Refugio núm. 9; Delano Hermanos, de 5 de Mayo; Librería de los Niños, esq. del Espíritu Santo y Portal de la Fruta; Litografía de San José el Real núm. 21; Litografía de Fernández"; el precio de suscripción: "En la capital cuatro reales adelantados. Números sueltos, un real. En los estados, seis reales adelantados, franco de porte. Números sueltos: real y medio." 28

La zona principal de difusión del semanario era el Distrito Federal; no se conocen ciertamente los lugares a los que llegaba, pero se deduce que tenía un público nacional, por comentarios aislados que mencionan el he-

28 Véase El Ahuizote, vol. I, 1874. 
cho, como una lista sobre los deudores a quienes reclaman pagos en Allende de Chihuahua; Cadereyta Jiménez; Otumba, Estado de México; Río Verde; Matehuala; Hermosillo, Sonora, etc. $y$ el precio de seis reales adelantados en los estados. ${ }^{29}$

El formato original del semanario es de $21 \times 32 \mathrm{~cm}$. (en 1876, en el tercero y cuarto tomo, se reduce varios centímetros) y consta de cuatro hojas en dos pliegos, de las cuales tienen caricaturas en litografía de página entera las planas núms. $1,4,5$ y 8 , con excepción de los números 29,31 y 43. En el núm. 29 se presenta una "Carta geográfica de la república mexicana", a cuatro páginas (parodia a la publicada por García Cubas en esa fecha), por lo que se cambia el formato normal y queda la ilustración en las páginas 2,3 , 6 y 7 , y los textos en la $1,4,5$ y 8 , suprimiéndose la caricatura de presentación. En el núm. 31 todo el periódico presenta pequeñas caricaturas que ilustran los diálogos. En el núm. 43 se presenta un juego de mesa llamado "El Viaje", a cuatro páginas, con los personajes, lugares y situaciones conocidos del momento, por lo que se cambia el formato y queda igual al del núm. 29.

En cuanto a la estructura jurídica del semanario, se deduce que se trata de una empresa en sociedad, aunque falta información acerca de qué tipo de sociedad era, quiénes eran los propietarios, quiénes los participantes financieros y en qué cantidad. Sobre la situación financiera puede preguntarse si las suscripciones, ventas y publi-

29 “¡Ojo! ¡Ojo!, ¡Ojo!”, El Ahuizote, vienes 25 septiembre 1874 , vol. I, núm. 34, p. 7 . cidad eran suficientes para hacer rentable el periódico, o si era subsidiado por alguien en particular, hecho que se sospecha a pesar de leerse varios años después la leyenda de presentación de El Hijo del Ahuizote: "Semanario feroz, aunque de nobles instin. tos políticos y sin subvenciones como su padre, matrero y calaverón" ${ }^{30}$

La redacción de El Ahuizote, de la cual se habló anteriormente, asumió responsabilidades diversas en lo concerniente al contenido, a la composición y a la presentación del semanario. En el periódico están firmados los editoriales, que aparecen en la sección "Claridades"; su autor es Juan Nepomuceno Mirafuentes; las caricaturas están por lo general firmadas por José Ma. Villasana, y sólo la primera caricatura del periódico (jueves 5 de febrero de 1874 , primera página) tiene las firmas de Villasana y Alamilla. Como vemos, Juan N. Mirafuentes tenía a su cargo el editorial; Villasana y Alamilla las cuatro hojas de caricaturas, y Riva Palacio, poco afecto a firmar, las distintas secciones presentadas en las tres hojas restantes de textos; posteriormente Luis G. de la Sierra se encargó de editar el semanario junto con Villasana. De los cuatro redactores originales, hay que notar que dos eran militares y periodistas y dos dibujantes de profesión, los cuatro comparten su tendencia de oposición al go-

${ }^{30}$ El Hijo del Ahuizote, semanario que comenzó a salir en agosto de 1885 como oposìtor y enemigo terrible del gobierno de Porfirio Diaz. Uno de sus fundadores fue el doctor Manuel Pérez Bibbins. Desapareció en 1902. Véase Porrúa, p. 100. 
bierno de Lerdo y su apoyo al grupo favorable a Porfirio Díaz.

En la redacción de los textos y en las caricaturas se puede observar que en ocasiones se maneja el nombre completo del personaje, a veces su función o empleo, o se hace alusión a él mencionando la relación que guarda con un personaje importante, y en ocasiones se presenta a alguien imaginario, como la Nación, la Constitución, el Pueblo, dotándolos de personalidad y características humanas o animales; igualmente es común designar al mismo personaje en distintas formas o nombres.

La identificación de los personajes caricaturizados requiere de un laborioso trabajo de investigación e ingenio, ya que no hay muchas fotografias de 1874; tal vez se podrían encontrar fotografias posteriores donde ha cambiado la figura, el peinado, el color de cabello, etc., aunque permanecen los rasgos característicos de las personas, obviamente exagerados por los dibujantes. Es muy frecuente que se presente al personaje en cuestión de varias maneras o en forma de objeto.

El bajísimo índice de personas que sabían leer era una limitación para la prensa periódica, algo que enfrentó triunfalmente el periodismo ilustrado, sobre todo este periódico, que capitalizó dicha situación y fue el que mayor espacio ocupó en caricaturas:

Al haber un gran porcentaje de analfobetos, la caricatura hablaba por sí misma; de cada diez personas sólo una sabia leer, y de ahí surge la influencia de la caricatura, ya que transmite plásticamente una idea sin necesidad de una lectura profunda, y con la poderosa arma del ridículo, los redactores de $E l$ Ahuizote lograron desprestigiar al gobierno, presentándolo como inmoral, inepto, hipócrita, apátrida, pelele, etcétera. ${ }^{31}$

De la superficie total del periódico, se desprende lo que forma su sustancia: el espacio de redacción. Este espacio muestra tres elementos diferentes: los títulos, las ilustraciones y los textos. Técnicamente, los títulos se distinguen del texto tanto por el tamaño como por el estilo y están destinados a llamar la atención del lector. Los títulos más importantes del semanario son "Claridades", "Porrazos", "Diversiones", y a veces ridiculiza al Diario Oficial presentando los mismos títulos que éste presenta: "Revista de los estados", "Actas del consejo", etcétera.

Frecuentemente los textos y las ilustraciones no llevan título, pero la colocación o contenido de éstos son suficientes para llamar la atención de los lectores. El semanario tiene varias sec. ciones más o menos continuas, a dos columnas, como: "Actas del consejo de ministros", donde satiriza y ridiculiza a Lerdo y su gabinete por medio de relatos absurdos e irónicos de las juntas de consejo de ministros; en "Porrazos" se denuncian, exponen y condenan actividades ilícitas, violencias, hechos concretos, etcétera; en "Colecciones de canciones del Ahuizote" se parodian canciones populares para criticar al gobierno, a los lerdistas o a Lerdo. La única sección escrita seria y formalmente es "Claridades", que pue-

${ }^{31}$ Acevedo, "Obra", 1975, p. 32. 
de considerarse como el editorial del periódico, firmada por Juan N. Mirafuentes, quien trata temas políticos para hacer exposiciones teóricas sobre la forma de gobernar, o caracteriza los gobiernos que ha tenido México, como pretexto para criticar o protestar contra Lerdo y su administración.

Actualmente la publicidad es un elemento vital en periódicos y revistas, tanto que puede dirigir la tendencia y objetivos de éstos; sin embargo, en los periódicos del siglo XIX, como El Ahuizote, la publicidad tiene una mínima importancia, ya que se intercalan pocos anuncios de comercio y de funciones de teatro, casi siempre los mismos y en la parte inferior de las hojas finales.

En las caricaturas políticas reside el éxito del periódico por la calidad de los dibujantes, por la gracia punzante, la agilidad y las críticas de actualidad. Como se dijo antes, generalmente están firmadas por Villasana o no tienen firma, pero se presume que fueron realizadas por Villasana y Alamilla en conjunto, ya que no se percibe un cambio notorio de estilo y hay gran parecido con las caricaturas de $\mathrm{La}$ Orquesta realizadas por Alamilla, y las de La Historia Danzante de Villasana.

Generalmente la caricatura de primera plana es un cuadro completo con leyenda al pie de página; las caricaturas centrales de las páginas 4 y 5 son dos cuadros complementarios con leyenda en la parte de abajo, a veces una historieta conectada con un párrafo continuo abarcando las dos paginas, o un cuadro completo a dos páginas con título. La caricatura final de la página 8 presenta, ya sea dos cua- dros complementarios, un cuadro completo o una composición de pequeños cuadros, siguiendo siempre con la misma tónica.

En cuanto a los asuntos contenidos en el semanario, se hizo una recopilación de temas generales; no es una clasificación exhaustiva, sino una aproximación primaria para conocer los temas más recurrentes en $\mathrm{El} \mathrm{Ahui-}$ zote durante 1874.

Antes de seguir adelante con esta clasificación, hay que mencionar algunas dificultades. Tradicionalmente, el contenido periodístico clasifica tres géneros: a) las informaciones: relatan hechos que se producen en todos los sectores de la actividad humana; $b$ ) los artículos: textos reflexivos que exponen ideas, comentan informaciones, discuten los asuntos más diversos; pueden ser editoriales, artículos firmados o no, etc.; c) la información con comentarios: son los más variados y utilizan cualquier elemento que esté a su alcance.

En estas clasificaciones el contenido de $E l$ Ahuizote entraría forzadamente, a excepción hecha de la sección "Claridades", que es sin lugar a duda un editorial. Por eso se decidió clasificar el contenido del semanario primordialmente en textos y caricatu. ras, aunque existe un catálogo de contenido con notas explicativas que se requieren para entender el periódico actualmente, pero ocupan más de 350 páginas, que no es posible reproducir aquí. ${ }^{32}$ Así, los temas tratados en el periódico El Ahuizote, en orden de recurrencia, son los siguientes:

${ }^{32}$ García Flores, "El Ahuizote", 1983. 
TEMAS GENERALES

Personajes públicos

ADMINISTRACIÓN LERDISTA

CONSTITUCIÓN POLÍTICA DE 1857

Poderes de LA UNIÓN

OBRAS PÚBLICAS

PRENSA PERIódICA

ESTADO DE LA FEDERACIÓN
SubTemas

Sebastián Lerdo de Tejada Ministros

Grupo lerdista

Gobernadores

Diputados

Otros personajes públicos

Gobierno

Gasto público-miseria del pueblo

Reelección

Oposición Lerdo-Mejía

Elecciones

Relaciones Exteriores

Hermanas de la caridad

Congreso

Suprema Corte de Justicia

Senado

Ministerio de Fomento

Ayuntamiento

Distrito Federal

Ferrocarriles

Tranvías

Lerdo-gobiernista

Oposición

Soberanía

Seguridad 
El Ahuizote no proclama concretamente una dependencia política en este año de 1874 -lo hará, como ya se dijo, hasta 1876, cuando sus hombres lleguen al poder-; Sebastián Lerdo de Tejada y su gabinete fueron el tema principal tratado por el periódico; de ellos se escribía y dibujaba en una forma despiadada, criticando su ineptitud, su favoritismo, sus vilezas y arbitrariedades, aunque en términos generales era cuestión de interpretación y actitud; la mayoría de las quejas (pero no todas) carecian de sustancia real, eran probablemente más una cuestión de personalidad que de principios, y siempre eran negativas.

La controversia principal fue de naturaleza política, definiéndose pronto en el gabinete y en aquellos que lo apoyaban; a la administración siempre se le presentaba orientada a beneficiar a Lerdo y a sus allegados, que de vez en cuando también "resultaban sacrificados en aras de la ambición del ejecutivo". El gasto público, que "era empleado para satisfacer los gustos del presidente y su arrogancia, contrastaban con la miseria del pueblo, que era explotado cínicamente por el gobierno"; los poderes de la Unión, "sumisos y serviles al ejecutivo tiránico y centralista", habían cedido ya, de acuerdo con los redactores, a la corrupción del gobierno.

Según El Ahuizote, la oposición era la única esperanza, y constantemente hacía alusiones al "momento en que el pueblo decidirá sacudirse el maligno gobierno que lo oprime". A lo largo del periódico se anuncia un levantamiento, que, al preguntarnos si era una predicción casual de los redacto- res o un anuncio de algo esperado, no puede aceptarse como una casualidad ingenua; evidentemente tenía un objetivo premeditado: ir preparando el camino para una sublevación, aunque en varias ocasiones se afirmó que no pretendía incitar al pueblo a tal cosa; sin embargo, el tono mismo del semanario es una incitación constante. Tampoco fue mera casualidad que $E l$ Ahuizote defendiera la misma postura que el Plan de la Noria y el futuro Plan de Tuxtepec: los ideales liberales eran los que guiaban al semanario, pero fue un espíritu de crítica y oposición particular al gobierno lo que le animó; esa radical oposición podría esperarse de un periódico liberal ante un gobierno monárquico o centralista, por ejemplo la oposición que el bisemanario $L a$ Orquesta sostuvo contra el imperio de Maximiliano, pero no de un periódico liberal contra un gobierno igualmente liberal, a menos que pertenecieran abandos distintos, como ocurría entre ellos.

Al mismo tiempo, pusieron en boca del pueblo palabras como:

nuestra sociedad ansía orden, justicia y libertad. La gran mayoría de la nación apoyará cualquier partido político que le ofrezca sinceramente tan preciosos bienes; la nación ve atentamente los trabajos de la oposición, que es su representante en la arena política. La ambición de los buenos patriotas debe concentrarse en procurar dar al país un gobierno honrado, ${ }^{33}$

33 "Claridades", "Exigencias nacionales", El Ahuizote, viernes 6 noviembre 1874 , vol. I, núm. 40, p. 3 . 
y hacen "predicciones" para un futuro próximo como:

1874. El año que muere y el año que nace, 1875

Pueblo, que en un tiempo rey alzarse libre le plugo sin más freno que la ley ahora, como manso buey dobla el cuellơ y lame el yugo.

Mas quizá del mal que lloras y lloras sin esperanza, traigo el remedio que imploras; quizá llegue entre mis horas la hora de la venganza. ${ }^{34}$

\section{CONSIDERACIONES FINALES}

El periodo generalmente denominado de la Restauración, comprendido entre el final de la intervención francesa y el comienzo del gobierno de Porfirio Díaz (1867-1876), fue una época de transición en que se tenían que resolver viejos problemas restantes de las épocas de la Reforma y el Imperio, y en el que surgió una nueva organización.

Esos problemas ejercieron dura presión sobre los gobiernos de dicho periodo, que tuvieron que concentrar sus energías en resolverlos. Primero restablecer la paz y el orden después del largo lapso de desórdenes civiles y de lucha militar, posteriormente una

34 "Tonteras", "1874. El año que muere y el año que nace. 1875", El Ahuizote, viernes 25 diciembre 1874 , vol. $\mathrm{I}$, núm. 7, p. 3 . reforma constitucional que reforzara al gobierno central y al poder ejecutivo en particular; existía también la tarea de reconstruir la desmantelada maquinaria administrativa, de aumentar el ingreso nacional, de dotar al país de modernas vías de comunicación (ferrocarriles, telégrafos, tranvías), de establecer bases para la inversión extranjera en comunión con el capital nacional, e incorporar en la ley orgánica la separación de la Iglesia y el Estado. Todo esto para transformar a México en una nación equilibrada, próspera y moderna, cuando la paz y el orden requerían tanto dinero como atención. La idea de la paz fue reiterada periódicamente por Lerdo durante su gobierno:

El señor Lerdo ha creído, y cree todavía con profunda convicción, que la base esencial para el desarrollo de las mejoras y el engrandecimiento de la república consiste en la paz, porque sin ésta los espíritus serios se desalientan y no se preocupan de aquellos proyectos que traen consigo la regeneración de los pueblos, meditados en la caima y desarrollados bajo la influencia pacífica del reposo y de la tranquilidad públicos. Las vías férreas, la colonización, los telégrafos, y todo aquello que cambia la situación de las naciones, no es posible que se realice si no hay paz y estabilidad; nada mejor puede hacer un gobierno que afianzar esta base indispensable de prosperidad y bienestar. 35

Éste fue el punto de partida de su política, y no vacilaría ante ningún

${ }^{35}$ Frank Knapp, Sebastián, 1962, pp. 266. 267 apud. Diario Oficial, 10 agosto 1874. 
obstáculo por conservarla; el momento legislativo más importante del periodo fueron las adiciones a la Constitución de las Leyes de Reforma, que era un cambio técnico que les daba un rango más elevado; pero Lerdo mostró un celo obstinado en aplicarlas, por lo que este asunto fue de vital importancia. Uno de los aspectos políticos más importantes, junto con la restitución del Senado, fue la libertad que ofreció a la prensa, por considerarla como la más preciada de las garantías constitucionales: "La libertad dela prensa, que protege y resguarda a las otras, será para mí inviolable, [...] de los excesos que se cometan por la prensa, el mejor correctivo es la misma prensa, ilustrada, libre, eco de todas las opiniones y de todos los partidos." 36 Esa prensa que Lerdo respetó con ciega devoción, lo atacó despiadadamente, convirtiéndose en un poderoso instrumento de la revolución y en una de las causas principales de su ulterior caída.

En el periodo comprendido entre 1872 y 1876 , la oposición al gobierno se reunió en un círculo cada vez mayor de periódicos hostiles que realizaron un ataque sistemático contra Lerdo de Tejada; de entre su grupo, $E l$ Ahuizote se destacó por el estilo irónico, satírico, sarcástico, característico de Vicente Riva Palacio, animado por las caricaturas de Villasana.

Villasana ridiculizó a Lerdo y a su gobierno con feroces caricaturas en todas las formas imaginables; hizo del Pueblo, de la Acción, de la Constitución, del Congreso (etcétera) perso-

${ }^{36}$ Diario Oficial, 28 julio 1872 , p. 1. najes dotados de vida, de pasiones y de odios, y a los más importantes hombres de ese momento, objetos y jugue. tes ridículos sin virtudes o calidades ejemplares.

La aparición de un semanario como éste, se dio al reunirse varias circunstancias especiales que lo hicieron único, tales como:

Una técnica de impresión menos laboriosa, que ofrecía su fidelidad al artista con un costo de producción mucho menor que la de grabado, por lo tanto susceptible de ser empleada popularmente.

Un grupo de escritores y dibujantes de gran capacidad intelectual, técnica e ingenio, quienes hacían uso del humor, el sarcasmo, la ironía, las parodias, el absurdo y, sobre todo, del ridículo en función de la crítica política.

La irrestricta libertad de imprenta, como en pocas ocasiones se tuvo en México, propia de un gobierno liberal a ultranza.

Un gobierno de características tan especiales como el de Lerdo de Tejada, quien llegó al poder inesperadamente recogiendo a su favor el descontento provocado por la reelección de Juárez, pero sin el respaldo popular, lo cual fue cada vez más evidente, junto con los errores políticos por él cometidos.

Un presidente con personalidad difícil y particular como la que poseía Lerdo de Tejada, que además era el único presidente soltero que ha tenido México en su historia.

La separación de Vicente Riva Palacio del bisemanario La Orquesta por motivos ideológicos concretos, ya que 
un hombre de acción como él buscaría la forma y el lugar para sacarlos a la luz y cumplir sus ideas liberales.

Casi todas estas circunstancias dieron lugar a que surgieran otros virulentos periódicos de oposición que atacaron al gobierno lerdista haciendo uso y abusando de la libertad de imprenta para "proteger y resguardar las garantías constitucionales del pueblo que representaban", de acuerdo con los ideales liberales. Sin embargo, el objetivo de El Ahuizote fue, expresamente, desprestigiar y ridiculizar a Lerdo y a su gobierno como apoyo a otro candidato. En el ánimo del público este periódico tuvo una influencia decisiva.

El biógrafo de Lerdo de Tejada, Frank A. Knapp Jr., escribió en su libro: "Como la prensa de oposición era irresponsable, elegía sus métodos sin ningún sentido de lo que es jugar limpio en política." ${ }^{37}$ Pero evidentemente El Ahuizote sí tenía responsabilidad, aunque a favor del grupo partidario de Porfirio Díaz; estaba en juego una silla presidencial y el futuro de una nación y, para ganarlas, hacían falta armas eficaces.

En 1876 los redactores de $E l$ Ahuizote apoyaron abiertamente la revolución de Tuxtepec, dejando a luz sus verdaderas intenciones, desechando la "casual e inocente" similitud entre los principios de dicho plan revolucionario con los del anterior Plan de la Noria y los suyos. "El Plan de Tuxtepec no tuvo mejor adalid, ni don Porfirio mejor capitán." 38

${ }^{37}$ Frank Knapp, Sebastián, 1962, p. 352.

38 Toussaint, 1934, p. XXVI.
"Yo, con la poderosa arma del ridículo, desprestigié a aquel gobierno inmoral y miné su poder para hacer forzoso el hundimiento."

El Ahuizote. ${ }^{39}$

\section{BIBLIOGRAFIA}

-Acevedo, Ma. Esther, "La obra de Constantino Escalante en el periódico $\mathrm{La}$ Orquesta", tesis de maestría en Historia del Arte, Universidad Iberoamericana, México, 1975.

-Bravo Ugarte, José, Periodistas y periódicos mexicanos, Jus, México, 1966.

-Cosío Villegas, Daniel, Historia moderna de México. La República Restaurada. La vida politica, Hermes, México, 1955.

-Cosmes, Francisco G., Historia general de México, Ramón S. Araluce, México, 1901.

-Diccionario Porrúa, Porrúa, México.

-Diccionario Salvat Ilustrado, Barcelona, 1971, vol. 8.

-Fernández Ledesma, Enrique, Historia crítica de la tipografía en la ciudad de México, impresos del siglo XIX, Secretaría de Educación Pública, México, 1935.

-García Flores-Chapa, María, "El Ahutzote 1874. Catálogo e índices de textos y caricaturas. Estudio de su línea y acción política frente al gobierno de $\mathrm{D}$. Sebastián Lerdo de Tejada (febrero-diciembre)", tesis de licenciatura en Historia, Universidad Iberoamericana, México, 1983.

-Kayser, Jacques, El periódico: estudio de morfología, de metodología y prensa comparada, $3^{\mathrm{a}}$ ed., CIESPAL, Quito, 1966.

-Knapp, Frank, Sebastián Lerdo de Tejada, Xalapa, Universidad Veracruzana, 1962.

39 "Tonteras", "Memorándum", El Ahuizote, viernes 29 diciembre 1876 , vol. $\mathrm{N}$, núm. 5, p. 3. 
-Leal, Luis, "El contenido de La Orquesta", Historia Mexicana, vII:3, (27), 1958.

-Mc Gowan, Gerald, Prensa y poder, El Colegio de México, México, 1978.

-Ortiz Monasterio, José, "Prólogo", a Riva Palacio, Los cuentos del general. Los ceros. Galería de Contemporáneos, Promexa, México, 1979.

-Pruneda, Salvador, La caricatura como arma política, CERRM, México, 1958.

-Riva Palacio, Vicente, Historia de la administración de don Sebastián Lerdo de Tejada, Imp. y Litografia del Padre Cobos, México.
-Torres Reed, Luis, "Antecedentes del periodismo humorístico", en $\mathrm{El}$ periodismo en México, UNAM, México, 1980.

-Toussaint, Manuel, La litografía en el siglo XIX, Estudios Neolitho M. Quesada B., México, 1934

\section{HEMEROGRAFIA}

-El Ahuizote, 1874.1876.

-El Hijo del Ahuizote, 1855-1902. -El Diario Oficial. 